This item was submitted to Loughborough's Research Repository by the author.

Items in Figshare are protected by copyright, with all rights reserved, unless otherwise indicated.

\title{
How do offshoring-related changes in job characteristics affect onshore managers' affective organizational commitment? The moderating role of perceived organizational valence
}

\section{PLEASE CITE THE PUBLISHED VERSION}

https://doi.org/10.1177/0268396220942237

\section{PUBLISHER}

SAGE Publications

\section{VERSION}

VoR (Version of Record)

\section{PUBLISHER STATEMENT}

This is an Open Access Article. It is published by SAGE Publications under the Creative Commons Attribution 4.0 International Licence (CC BY). Full details of this licence are available at: https://creativecommons.org/licenses/by/4.0/

\section{LICENCE}

CC BY 4.0

\section{REPOSITORY RECORD}

Zimmermann, Angelika, Eleni Lioliu, and Joao Oliveira. 2020. "How Do Offshoring-related Changes in Job Characteristics Affect Onshore Managers' Affective Organizational Commitment? the Moderating Role of Perceived Organizational Valence". Loughborough University. https://hdl.handle.net/2134/12514937.v1. 


\title{
How do offshoring-related changes in job characteristics affect onshore managers' affective organizational commitment? The moderating role of perceived organizational valence
}

Journal of Information Technology 2020, Vol. 35(4) 316-336 (C) Association for Information Technology Trust 2020 (c) (i)

Article reuse guidelines: sagepub.com/journals-permissions DOI: 10.1 I 77//0268396220942237 Journals.sagepub.com/jinf

(S)AGE

\author{
Angelika Zimmermann' ${ }^{(\mathbb{D})}$, Eleni Lioliou ${ }^{2}$ and João S Oliveira'
}

\begin{abstract}
Offshoring - the transfer of work activities to providers in offshore countries - has for some time affected the nature of work in onshore locations. Not much is however known about the reactions of onshore job incumbents to such changes. In this article, we use a survey of UK firms to examine the relationship between perceived changes in onshore managers' work characteristics induced by information systems offshoring and managers' affective organizational commitment. We found that a perceived increase in onshore managers' job complexity was associated with higher affective organizational commitment only if managers also perceived organizational valence, that is, only if they believed that information systems offshoring benefited their organization. A perceived increase in cross-cultural work was associated with higher affective organizational commitment, and this association was positively moderated by managers' perceptions of organizational valence. Using the offshoring context, our findings provide insights into consequences of contemporary changes in the nature of work in developed countries and to explain the diverse reactions of onshore job incumbents to such changes.
\end{abstract}

\section{Keywords}

Information systems offshoring, work characteristics, work design, job design, organizational valence

\section{Introduction}

The globalization of contemporary business, underpinned by modern information technologies, has enabled organizations to distribute their operations across multiple countries. This redistribution has arguably led to some of the most prominent changes in work in the Western world. Offshoring - the transfer of work to internal or external providers in an offshore location-has played an important part in this development. While emerging evidence suggests how offshoring affects the nature of work in onshore locations, we know little about how employees react to these changes. Drawing on insights from research on offshoring, job design, and organizational change, this article investigates how offshoring-related changes in certain job characteristics - job complexity and cross-cultural workaffect onshore managers' affective organizational commitment. Moreover, we explore the moderating and direct effects of perceived organizational valence, that is, the perceived benefit of offshoring for the organization.

There is a wide debate on the consequences that offshoring has for onshore jobs at the country level. For the information systems (IS) sector in particular, it appears unavoidable that a major part of IS work is (and will be) moving to emerging economies. Emerging countries offer not only cost arbitrage but also an abundance of highly skilled IS personnel. These developments have raised a lot of concerns for the future of IS in advanced countries

\footnotetext{
'Loughborough University, UK

${ }^{2}$ Queen Mary University of London, UK

\section{Corresponding author:}

Angelika Zimmermann, School of Business and Economics, Loughborough University, Loughborough LEII 3TU, UK.

Email: a.zimmermann@lboro.ac.uk
} 
(Beulen, 2010; Gupta, 2010; Hirschheim and Newman, 2010; Khan and Lacity, 2014; Weber, 2004).

At the same time, it has long been argued that offshoring of lower end, routine tasks entails a concentration of higher end, more complex jobs in the onshore countries (DavisBlake and Broschak, 2009; Goos et al., 2014; Ottaviano et al., 2013). For the IS sector, the argument goes that offshoring of coding tasks necessitates Western IS to concentrate more strongly on customer facing, high-complexity work such as business process modeling and enterprise architecture, which require in-depth business knowledge and technical expertise (Hirschheim and Newman, 2010). On the other hand, increasingly complex IS tasks are now offshored and higher end, complex tasks are no longer a privilege of Western offices. A new stronghold of onshore sites may therefore reside in strategy creation and information exploitation tasks that are hard to offshore because they require significant knowledge of the business as a whole (Beulen, 2010).

Only a small number of studies have looked at how, at the microlevel, employees react to offshoring-induced changes to their work. It here appears that onshore employees respond to these changes in different ways. The move of routine IS tasks to offshore destinations is by some employees regarded as an opportunity to concentrate on more complex work, and by others as a threat to their own technical expertise or career (Metiu, 2006), leading to either cooperation or resistance to offshoring (Zimmermann et al., 2013; Zimmermann and Ravishankar, 2011). Similarly, the need to concentrate on international coordination and mentoring can be regarded as enriching or as an additional burden, resulting in varying degrees of support for the offshoring operation (Kelly and Noonan, 2008; McCann, 2014; Zimmermann et al., 2013; Zimmermann and Ravishankar, 2016).

This research on employee reactions to offshoring relies only on a small number of case studies which use qualitative interviewing and do not make use of established quantitative scales. We therefore turn to the wellestablished literature on work design to explore employee reactions in more depth. This literature provides a large body of quantitative evidence on the effects that certain "work characteristics" have on employee attitudes, behaviors, and well-being (Hackman and Oldham, 1980; Humphrey et al., 2007; Parker, 2014 for reviews). Following the terminology of work design, some of the aforementioned changes in onshore jobs can be described as changed work characteristics. In particular, the greater focus on highly skilled and complex tasks can be classified as increased "job complexity" (Morgeson and Humphrey, 2006). Moreover, the new requirement of working and coordinating across cultures can be captured by what we call "cross-cultural work," a new work characteristic that is likely to be core to the offshoring context. By introducing and studying this new work characteristic, we respond to recent calls in the management literature for more research on the changing nature of work (Barley et al., 2017), and requests in the work design literature for more research on social and contemporary work characteristics, taking into account the influence of globalization (Grant and Parker, 2009; Parker, 2014; Parker et al., 2017).

The work design literature suggests that increased job complexity and social interactions are associated with positive outcomes regarding employee attitudes, behaviors, and well-being (Humphrey et al., 2007). This observation seems to contradict the above-mentioned finding that employees can react either positively or negatively to changes in their jobs after offshoring. It is therefore important to further establish what effects offshoring-related changes in work characteristics have on employee-level outcomes and to identify what factors impinge upon this relationship.

In this study, we focus on affective organizational commitment as an important employee-level outcome. In the context of offshoring, affective organizational commitment is likely to be important because employees have to support the organization's offshoring operation, for example, by transferring knowledge and mentoring offshore colleagues (see Zimmermann and Ravishankar, 2016). Strong organizational commitment is likely to reinforce such effort (Mowday et al., 1979), but can suffer when employees feel their job has deteriorated through offshoring (McCann, 2014).

We further argue that the degree to which changes in work characteristics affect organizational commitment depends on perceived organizational valence, that is, employees' perceptions of the benefits that IS offshoring has for the organization. Drawing on the organizational change literature (Fedor et al., 2006; Holt et al., 2007; Rafferty et al., 2013; Weiner, 2009), we reason that employees who do not believe that IS offshoring is beneficial for the organization are less likely to endorse the organization's decision to offshore. In this case, we argue that increased job complexity and cross-cultural work will have a less positive effect on employees' organizational commitment. We thus reason that perceptions of organizational valence will moderate the relationship between perceived changes in work characteristics and affective organizational commitment. In addition, perceptions of offshoring benefits are likely to have a direct effect on employees' affective commitment to the organization. An overview of the construct definitions is provided in Table 1.

In our study, we focus on middle managers, a group of employees that tends to be involved in complex international collaboration, coordination, and management after offshoring, and whose work therefore tends to be affected through offshoring. We thus take a more focused view compared to prior work on employee reactions to offshoring, which tends to comprise different hierarchical levels of 
Table I. Definitions of the main constructs.

\begin{tabular}{|c|c|}
\hline Construct & Definition \\
\hline Job complexity & $\begin{array}{l}\text { The extent to which the tasks on a job are complex and difficult to perform (Morgeson } \\
\text { and Humphrey, 2006: 1323) }\end{array}$ \\
\hline Cross-cultural work & Individuals' involvement in cross-cultural interactions as part of their job \\
\hline Affective organizational commitment & $\begin{array}{l}\text { An individual's strong belief in and acceptance of the organization's goals and values, a } \\
\text { willingness to exert considerable effort on behalf of the organization, and a strong desire } \\
\text { to maintain membership in the organization (Mowday et al., 1979: 226) }\end{array}$ \\
\hline \multirow{4}{*}{ Organizational valence } & General definition: \\
\hline & $\begin{array}{l}\text { The extent to which one feels that the organization will or will not benefit from the } \\
\text { implementation of the prospective change (Holt et al., 2007: 239) }\end{array}$ \\
\hline & Definition for the offshoring context: \\
\hline & Individuals' perception of the benefit that IS offshoring has for their organization. \\
\hline
\end{tabular}

IS: information systems.

employees (e.g. Maertz et al., 2010; McCann, 2014; Metiu, 2006; Zimmermann and Ravishankar, 2011).

In sum, we examine the following research questions: (1) How do perceived offshoring-related changes in onshore managers' work characteristics - namely perceived increases in (a) job complexity and (b) cross-cultural work - affect the levels of onshore managers' affective organizational commitment? (2) Are these effects moderated by perceived organizational valence? and (3) Does organizational valence have a direct effect on affective organizational commitment? By examining "perceived" rather than "actual" changes in work characteristics, we ensure that we capture changes that were noticeable and significant in the eyes of our participants. For ease of expression, we do not add the descriptor "perceived" every time we mention the changes in the text.

Our research is both novel and timely. Although IS offshoring is increasingly prevalent, there are, to our knowledge, no systematic investigations of the effect that offshoring-related changes in work characteristics have on employee attitudes. Moreover, we combine several literatures that have not been used in conjunction before, namely research on offshoring, work design, and organizational change. This integrative approach yields a more solid conceptual and empirical basis for research on the consequences of IS offshoring for the nature of contemporary work and resultant employee attitudes and helps us explain some of the contradictions in employees' responses to offshoring.

In what follows, we develop our arguments by combining insights from work design and offshoring research. We first reflect on changes in work characteristics resulting from offshoring. We then highlight employees' reactions to these changes, with a particular focus on affective organizational commitment. This leads to our first set of hypotheses (1a and 1b). Following this, we draw on the organizational change literature to argue for moderating and direct effects of organizational valence (hypotheses 2a-2c). After presenting our methods and results, we discuss the contributions to research on IS offshoring and work design, as well as practical implications, limitations, and directions for future research.

\section{Background and hypotheses}

\section{Changes in managerial work characteristics through offshoring}

In order to describe work characteristics in relation to IS offshoring, it is useful to draw on the work design literature. Work design research is generally concerned with how tasks, roles, and jobs are structured to achieve favorable outcomes for individuals and organizations (Grant and Parker, 2009). This research has its roots in the notion of job enrichment, crystallized in Hackman and Oldham's (1980) job characteristics model (JCM). The JCM posits that five characteristics of enriched jobs - high skill variety, task significance, task identity, autonomy, and feedback - create psychological states of "experienced meaningfulness," "experienced responsibility," and "knowledge of results," which lead to positive work outcomes, including behavioral, attitudinal, and well-being outcomes. Examples of such outcomes are job satisfaction, performance, burnout, and organizational commitment.

The last two decades have produced a large body of evidence to support these relationships (Humphrey et al., 2007; Parker, 2014, for reviews). The JCM has also been extended to include additional characteristics, such as job complexity (see Morgeson and Humphrey, 2006). Recently, there have been calls for more research on social and contemporary work characteristics and for taking into account the influence of globalization and cross-cultural working (Grant and Parker, 2009; Parker, 2014; Parker et al., 2017). The offshoring context lends itself to consider these aspects in depth. Having emerged relatively recently, it is a contemporary, cross-cultural work context. At the same time, little is yet known about changes in work characteristics and their psychological consequences in this setting. 
We argue that certain work characteristics described in work design research are particularly likely to be affected by offshoring. As mentioned, there are arguments that offshoring leads to an increase in higher skilled work (United Nations, 2005), which has also been described as more complex (Goos et al., 2014; Ottaviano et al., 2013; RobertNicaud, 2008). Using the terminology of work design, such job complexity can be characterized as "the extent to which the tasks on a job are complex and difficult to perform" (Morgeson and Humphrey, 2006: 1323). A primary explanation for increased job complexity is that offshoring leads to productivity gains for onshore countries, allowing for the creation of more jobs in the highly skilled sector (Aspray et al., 2006; Mankiw and Swagel, 2006). Moreover, offshoring is seen to increase the complexity of knowledge-intensive jobs that already exist in the onshore countries (Davis-Blake and Broschak, 2009). The offshoring of routine tasks allows onshore employees and firms to concentrate to a greater extent on their complex tasks, such as research and development (e.g. Davis-Blake and Broschak, 2009; Goos et al., 2014; Ottaviano et al., 2013; Zimmermann and Ravishankar, 2011). In the case that knowledge intensive rather than routine IS tasks are offshored, onshore managers may still be able to concentrate on tasks that require significant knowledge of the business as a whole, such as strategy creation and information exploitation (Beulen, 2010).

Moreover, offshoring typically requires onshore employees (and managers in particular) to work to a greater extent internationally, namely to distribute and coordinate task components across national boundaries and manage multiple interfaces and time zones (Nurmi and Hinds, 2016). The international offshoring set-up has been shown to create several challenges for IS professionals, such as an increased need for knowledge sharing and transfer (Zimmermann and Ravishankar, 2014), issues of data security and intellectual property protection (Goodman and Ramer, 2007) and managing risks, which has long been recognized as a central problem in offshore software development (Nakatsu and Iacovou, 2009).

Given the international setting of offshoring, IS professionals are now also increasingly required to coordinate, communicate, and interact with colleagues from different cultural backgrounds (Avison and Banks, 2008) and thus to bridge cultural barriers such as divergent expectations concerning working practices and communication norms (see Hinds et al., 2011, for a review of management studies on global work). Studies in IS offshoring have thus argued for the crucial role of cultural fit between the partnering organizations (Abbott et al., 2013; Carmel and Tjia, 2005; Jarvenpaa and Mao, 2008) and for the importance of cross-cultural competence (Johnson et al., 2006), language proficiency, and rich communication skills, particularly in cross-border collaborations on knowledge-intensive tasks such as requirements specification, feasibility analysis, code development, testing, and user acceptance (Davis et al., 2006).
We regard "cross-cultural work" as a distinct work characteristic, defined as individuals' involvement in cross-cultural interactions as part of their job. In our study, we single out three aspects of cross-cultural work: coordinating work across national boundaries, dealing with cross-cultural differences in work practices, and dealing with cross-cultural differences in communication styles. In examining these behavioral aspects of cross-cultural work, we adopt a behavioral view that focuses on work practices as cultural productions of culture, rather than on the underlying cultural value systems (Hinds et al., 2011; Morris et al., 2008). Instead of specifying the nature of cultural differences, we are here interested in the extent to which job incumbents have to cross-cultural boundaries after the event of offshoring. The named requirements of cross-cultural work have not been included in previous work design research and can therefore be distinguished clearly from the established work characteristics of the JCM. We regard cross-cultural work as a social work characteristic, because it reflects the extent to which onshore members have to interact with members of different nationalities. By examining this work characteristic, we hence respond to the mentioned pleas for more research on the social characteristics of modern work (Grant and Parker, 2009; Parker, 2014).

It can be argued that IS offshoring could affect additional work characteristics of the JCM. For example, IS offshoring may reduce task identity and significance, if it requires work to be divided into packages that are distributed across the globe, resulting in less complete onshore tasks. However, IS offshoring often involves a high degree of task interdependence and collaboration between onshore and offshore sites which requires onshore employees to have an overview of the overall project and take responsibility for the final output (Zimmermann and Ravishankar, 2016). In this case, task identity and significance would still be high. We therefore focus on those job characteristics which reflect the most frequently described offshoring-related changes to onshore work, job complexity, and cross-cultural work. These characteristics include a well-established work characteristic - job complexity — and a new, social work characteristic - crosscultural work - which are key for the offshoring setting. This choice facilitates a comparison with extant work design research on a previously studied work characteristic (complexity), while also contextualizing the JCM and thereby addressing the need for more research on social and contemporary work characteristics, and extending the JCM through the characteristic "cross-cultural work."

\section{Reactions to changes in managerial work characteristics - organizational commitment}

As stated in the introduction, only a small number of studies have examined how employees react to offshoringinduced changes to their work. The extant studies have highlighted that employees react differently to perceived 
new work requirements, depending on their evaluations of the requirements, for example, by either supporting or avoiding the transfer of tasks (Metiu, 2006; Zimmermann et al., 2013; Zimmermann and Ravishankar, 2011, 2016). If we turn to the literature on work design, however, we find long-standing support for the view that enriched work, characterized among others by the work characteristics in question here (job complexity and social work characteristics), has positive effects on employee-level outcomes. As mentioned, the work design literature suggests that through their effects on psychological states, work characteristics support favorable attitudinal, behavioral, and well-being outcomes (Parker, 2014). It is therefore worth investigating how offshoring-related changes in work characteristics affect employee-level outcomes.

For our study, we chose affective organizational commitment as the outcome of interest. In line with Mowday et al. (1979: 226), we define organizational commitment as an individual's strong belief in and acceptance of the organization's goals and values, a willingness to exert considerable effort on behalf of the organization, and a strong desire to maintain membership in the organization. Meyer and Allen (1991) later termed such commitment "affective" commitment in distinction from continuance commitment (the need to maintain employment in the organization) and normative commitment (the obligation to maintain employment in the organization). For reasons of parsimony, we include only affective commitment, the most relevant type of commitment in our context. While continuance and normative commitment are tied to extrinsic motivators, namely "need" and "obligation," we hold that perceived changes in work characteristics will impact upon the degree to which organizational members are willing to spend effort and stay with the firm, regardless of external pressures such as need or obligation. This is in line with Hackman and Oldham's (1975) reasoning that work characteristics affect attitudinal outcomes through their effect on psychological states such as experienced meaningfulness, that is, the degree to which an employee feels the job has value and importance. External necessity, in terms of need or obligation, is not part of this model.

While offshoring-related changes in work characteristics are also likely to affect other outcomes in the JCM, such as performance and job satisfaction, we see intrinsic value in examining affective organizational commitment as an outcome. Organizational commitment is generally paramount for firms aiming to develop highly committed knowledge workers, minimize employee turnover, and thereby enhance firm performance. A meta-analysis by Meyer et al. (2002) thus suggests that affective commitment has "favorable correlations with organization-relevant (attendance, performance, and organizational citizenship behavior) and employee-relevant (stress and work-family conflict) outcomes" (p. 20). In the same vein, proponents of "high commitment work practices" claim that developing highly committed employees is central to the competitive advantage of a firm (Huselid, 1995).

In the context of offshoring, affective organizational commitment is also important because employees have to support the offshoring operation in order to make it successful. They have to be willing to spend effort, for example, in transferring knowledge and mentoring offshore colleagues, and allocating tasks in line with the offshoring strategy (Zimmermann and Ravishankar, 2016). When affectively committed to the organization, employees are more likely to engage in such effort on behalf of the organization. Conversely, there are indications that negative evaluations of offshoring-related work changes can decrease employees' organizational commitment. McCann (2014) found "detachment and disaffection" in banking and insurance employees who regarded offshoring as a cost-cutting exercise that lead to "fragmented and increasingly complex workplaces." For these employees, offshoring meant "having to straddle different geographies, operational systems and working cultures" without an increase in skill levels in their lead firms (McCann, 2014: 255). Organizational commitment is likely to suffer particularly if offshoring is combined with downsizing (see Niederman et al., 2006). Maertz et al. (2010), for example, demonstrate that survivors of downsizing through offshoring, compared to a group who experienced no downsizing, perceived lower "affective attachment" to the organization.

\section{Relationship of organizational commitment with perceived job complexity and cross- cultural work}

Based on evidence from work design research, we suggest that affective organizational commitment is related to changes in the work characteristics in question here-job complexity and cross-cultural work (see Figure 1). Job complexity, to start with, has only relatively recently been identified as a distinct work characteristic (Morgeson and Humphrey, 2006), as earlier work design research equates job complexity with job enrichment, that is, the composite of the job characteristics in the JCM (skill variety, task identity, etc.). For this reason, there is little research regarding the effects of job complexity as a separate job characteristic (rather than the composite) on attitudinal outcomes. Notably, however, Humphrey et al.'s (2007) review of work design research hypothesizes a positive relationship between thus-defined job complexity and organizational commitment. In the same vein, we reason that increased job complexity will enrich onshore managers' work in terms of perceived value and importance and thereby strengthen their affective organizational commitment. As mentioned before, we consider that such an increase in job complexity is more likely to matter if managers recognize this increase. We hence concentrate on the perceived (i.e. reported rather than "actual") increase in job complexity. Based on this reasoning, we hypothesize: 


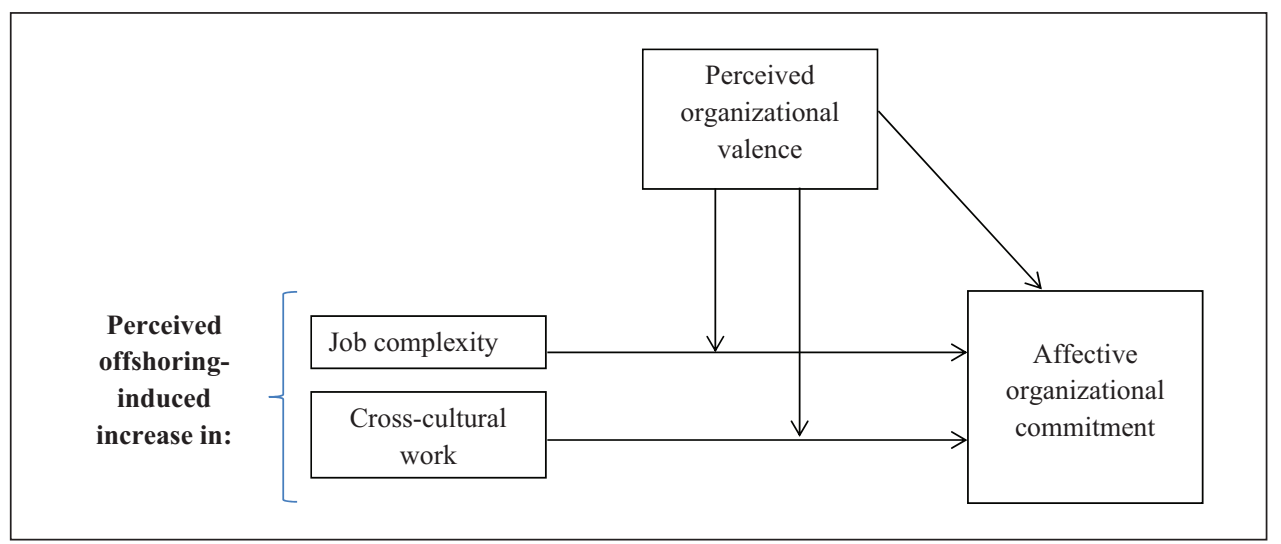

Figure I. Conceptual model.

Hypothesis 1a. The perceived increase in job complexity after offshoring is associated with higher levels of managers' affective organizational commitment.

Concerning cross-cultural work, we found only one study that examines a related construct, namely "global virtual work," through the lens of the JCM. Nurmi and Hinds (2016) demonstrate that engineers (including IS engineers) perceived global virtual work as having greater job complexity (defined again as the composite of autonomy, feedback, skill variety, task identity, and task significance). While organizational commitment was not included in their study, job complexity was found to moderate the effects of global virtual work on three other employee-level outcomes: job satisfaction, work engagement, and innovative performance. Notably, Nurmi and Hinds (2016) do not regard global virtual work as a work characteristic per se, but measure it as a dichotomous variable capturing whether a respondent was in a different country than any of his or her co-workers. This variable is then linked with the named work characteristics of the JCM model. Despite these differences, Nurmi and Hinds' (2016) research is informative for our study. Their finding that global virtual work is beneficial for job complexity, and through this increases job satisfaction, indicates that cross-cultural work may have a positive association with organizational commitment, given that organizational commitment has been linked with job complexity (e.g. Pentareddy and Suganthi, 2015) as well as job satisfaction (Welsch and LaVan, 1981). We thus assume that crosscultural work is part of job enrichment, which increases the perceived value and importance of onshore managers' work, and thereby has a positive effect on affective commitment to the organization. We thus hypothesize:

Hypothesis $1 b$. The perceived increase in cross-cultural work after offshoring is associated with higher levels of managers' affective organizational commitment.

\section{The moderating role of perceived organizational valence}

While the reviewed work design literature suggests a positive association of the work characteristics in question with affective organizational commitment, we are still confronted with the contrasting finding in the IS offshoring literature that employees can react either positively or negatively to offshoring and to resultant changes in their work involving increased job complexity and cross-cultural work (Zimmermann et al., 2013; Zimmermann and Ravishankar, 2011, 2016). Prior IS offshoring research also suggests that employees' reactions to offshoring depend on their evaluations of its consequences for the organization. In the context of IS offshoring, employees can, for example, hold different views on offshoring outcomes for organizational performance, efficiency, and cost savings. Employees opinions can also differ on whether offshoring may cause the onshore part of the organization to lose core competences, combined with a danger of over-dependence on the offshore unit (Dibbern et al., 2008). If employees are convinced that offshoring is detrimental to task performance and does not improve costs or efficiency (e.g. through additional coordination requirements), they are less likely to support the offshoring operation (Zimmermann and Ravishankar, 2016). We can therefore assume that employees who do not believe that IS offshoring is beneficial for the organization and therefore "makes sense" will not subscribe to the organization's decision to offshore. In this case, we argue that increased job complexity and crosscultural work will have less positive effects on organizational commitment. Conversely, employees who believe that IS offshoring is beneficial for the organization, for example, in terms of cost saving, efficiency, and international distribution of competences, are more likely to endorse the organization's decision to offshore. The positive effect of increased job complexity and cross-cultural work on employees' organizational commitment will then be amplified. 
This line of reasoning can be supported by the notion of "organizational valence," defined as "the extent to which one feels that the organization will or will not benefit from the implementation of the prospective change" (Holt et al., 2007: 239). This concept was developed in the organizational change literature, demonstrating that organizational change affects attitudinal outcomes such as organizational commitment (Fedor et al., 2006; Oreg et al., 2011), and this effect is moderated by organizational valence (Rafferty et al., 2013). The more organizational members perceive change as important, beneficial, and worthwhile for the organization, the more they will support it (Weiner, 2009), and the less likely they are therefore to demonstrate negative attitudinal outcomes. Considering offshoring-related changes in work characteristics as a form of organizational change, we thus argue that organizational valence positively moderates the effect of changes in work characteristics on affective organizational commitment. We hypothesize:

Hypothesis $2 a$. Perceived organizational valence positively moderates the association between the perceived increase in job complexity and the levels of affective organizational commitment.

Hypothesis $2 b$. Perceived organizational valence positively moderates the association between the perceived increase in cross-cultural work and the levels of affective organizational commitment.

Perceived organizational valence is also likely to have a direct effect on affective organizational commitment. We assume that employees who believe that the organization has taken a wise decision in conducting offshoring are likely to develop a stronger belief in the organization's goals and values, a stronger willingness to exert considerable effort on behalf of the organization, and a stronger desire to maintain membership in the organization - that is, stronger affective organizational commitment (Mowday et al., 1979: 226). Looking at the organizational change literature, this argument can be supported by Holt et al.'s (2007) finding of a positive relationship between organizational appropriateness, a composite of organizational valence and discrepancy, and affective organizational commitment. We therefore hypothesize:

Hypothesis 2c. Higher levels of perceived organizational valence are associated with higher levels of affective organizational commitment.

One may ask whether organizational commitment could have a reverse effect on perceived organizational valence, that is, that managers who are committed to the organization perceive organizational change initiatives such as offshoring more positively. There are a few studies that seem to imply this. Stouten et al. (2018: 18) argue that the overall level of employee commitment to the organization itself appears to facilitate change acceptance, referring to Iverson (1996). Iverson (1996) indeed showed that organizational commitment had a positive effect on acceptance of organizational change, which they explain by committed employees being more productive and more adaptable to change. In the same vein, Peccei et al. (2011) found that organizational commitment influenced resistance to change. However, both of these studies do not include perceived organizational valence as a variable. McKay et al. (2013) in turn found a positive effect of affective organizational commitment on personal valence, but not on appropriateness, a construct that includes organizational valence. There is hence no significant support for the influence of organizational commitment on perceived valence. By contrast, as outlined, the organizational change literature (Fedor et al., 2006; Holt et al., 2007; Oreg et al., 2011; Rafferty et al., 2013) provides strong support for a causal influence of valence on organizational commitment. We further reason that being strongly committed to the organization does not necessarily make managers less critical about the organization's initiatives, but strongly committed managers may still not perceive strong benefits in the organization's offshoring initiative. To be more specific, even if managers are (according to our operationalization of affective organizational commitment) willing to put in effort beyond the normally expected, feel that their values are similar to their organizations, are proud to tell others that they are part of the organization, feel that the organization has inspired the best in them regarding performance, and they care about the fate of the organization, they may still disagree with the organization's offshoring initiative and its benefits.

\section{Methods}

\section{Participants}

We conducted an online survey on a sample of UK firms, the United Kingdom being one of the major countries involved in IS offshoring. We collected our data in July 2016. We concentrated on offshoring to captive (i.e. in-house) centers of firms, also termed offshore development centers (ODCs). Our investigation included medium and larger firms, given that in-house offshoring is here more typical than in smaller firms. We further focused our study on organizations that were offshoring software-related work. The sample included firms in various industries including, but not limited to, the following: financial services; retail; manufacturing; information technology and telecommunications; business and professional services; media, leisure, and entertainment; construction and engineering; consumer services; transport and travel; and logistics.

We applied a key informant methodology for our data collection, by including employees at each firm who would 
have knowledge and experience regarding the issues of our investigation (see Goo et al., 2009; Kumar et al., 1993; Segars and Grover, 1998). In particular, we included directors and managers of functional business areas (i.e. not just IT), as well as managers of software development projects. Through screening questions, we ensured that the business unit of all respondents had conducted offshoring of software development, that aspects of the respondents' work had changed as a result of this offshoring, that their business unit had been affected by this offshoring, and that the respondents were familiar with the offshoring operation (i.e. with how services provided by the offshore units were scoped and delivered).

A total of 3007 individuals employed in UK companies were initially contacted. Out of these, 570 individuals satisfied all of the criteria in our screening questions. In total, we gathered 150 fully completed questionnaires, resulting in a response rate of $26.3 \%$. Based on the data, there was not a significant difference between the demographic characteristics of the firms that responded and those that did not, giving no reason to assume a non-response bias. The participants were given a short description of the survey and assured that the results from the survey would be used only for academic purposes. Respondents had the option to terminate the survey at any stage.

\section{Measures and control variables}

Perceived increase in job complexity. To measure perceived changes in job complexity, we used three items from the reverse-coded scale on job complexity developed by Morgeson and Humphrey (2006). Each item was rated on a 5 -point scale, ranging from (1) strongly disagree to (5) strongly agree. We adapted the items to reflect the perceived increase in job complexity that had resulted from offshoring. We hence provided the prompt "As a result of offshoring" to make clear that we were asking for offshoring-induced job characteristics. We then listed the following reverse-scored items: (1) "the job now requires that I only do one task or activity at a time," (2) "the job now comprises less complicated tasks," and (3) "the job now involves performing simpler tasks."

Perceived increase in cross-cultural work. In order to measure the perceived extent to which cross-cultural work had increased or decreased after offshoring, we developed our own measure based on general descriptions of cross-cultural work (see Hinds et al., 2011), and reflections by Davis-Blake and Broschak (2009) and Zimmermann and Ravishankar (2016) on cross-cultural work requirements after offshoring. Our measure hence comprised the requirement for international coordination and dealing with crosscultural differences in work practices and communication styles. We used a 3-item scale, ranging from (1) to a much smaller extent to (5) to a much greater extent. Following the prompt "As a result of offshoring, my job now requires me to," we included the following items: (1) "coordinate work across national boundaries," (2) "deal with cross-cultural differences in work practices," and (3) "deal with cross-cultural differences in communication styles."

Perceived organizational valence. We measured perceived organizational valence using six items, originating from the work of Holt et al. (2007). We adapted the items to capture the extent to which individuals perceived offshoring as beneficial to the organization. Each item was rated on a 5-point scale, ranging from (1) strongly disagree to (5) strongly agree. To make clear that respondents had to refer to their initial evaluation at the time of implementation, rather than their current evaluation, we provided the following introductory sentence: "Please cast your mind back to the time when this offshoring began to be implemented in your business unit or project. The following questions ask about your thoughts and feeling at that time.," followed by the prompt "At the time when this offshoring was implemented ..."We then presented the following items: (1) "I thought the organization would benefit from offshoring," (2) "I thought our organization would be more productive when implementing offshoring," (3) "I believed that when we adopted this change, we would be better equipped to meet our customers' needs," and (4) "I believed offshoring would improve our organization's overall efficiency." It was important to present these items in the past rather than present tense to capture perceived organizational valence at an early stage of offshoring, when organizational valence has the potential to shape managers' reactions to the extent of change.

Affective organizational commitment. We measured affective organizational commitment using four items, based on the scale developed by Hartline et al. (2000). Each item was rated on a 5-point scale, ranging from (1) strongly disagree to (5) strongly agree. We provided the prompt "Since offshoring" to indicate that answers were to relate to the time after the offshoring had been implemented. This was to prevent respondents referring to their organizational commitment before or at the start of offshoring. Succeeding the prompt, the following items were provided: (1) "I have been willing to put in a great deal of effort beyond that normally expected in order to make this organization be successful," (2) "I have been proud to tell others that I am a part of this organization," (3) "This organization has inspired the very best in me in the way of job performance," and (4) "I really care about the fate of this organization."

Control variables. In our examination, we first controlled for the industry of the participants, assuming that organizational commitment may vary across industries, for example, due to differences in organizational climates between industries. We asked participants to locate their organization within a choice of sectors, including (1) Finance, (2) Retail, (3) 
Manufacturing, (4) IT, and (5) Other industries. We also controlled for employee tenure, considering two potential influences: first, employees who have already stayed with a company for a long period may also be more committed to it. Second, prior studies have found that new employees tend to react more favorably toward various organizational practices and changes during their first time with organizations, which is commonly referred to as the "honeymoon period" (Wright and Bonett, 2002). It is therefore likely that new employees, compared to employees with intermediate tenure, react more positively to organizational changes. We asked individuals "For how long have you been in your current job?" and included the following items: (1) less than a year, (2) more than a year and less than 3 years, and (3) more than 3 years. These intervals were chosen based on common training periods and turnover rates in the SW industry, indicating that the honeymoon stage would not last longer than a year and after 3 years employees would be well acquainted with the organization. Assuming that consequences of offshoring-related changes may emerge increasingly over time, we further controlled for the time that had elapsed since the initiation of offshoring in the relevant business unit. We asked participants "How long ago did offshoring first take place within your business unit?" and included the following items: (1) less than a year, (2) more than a year and less than 3 years, and (3) more than 3 years. These intervals were chosen in view of likely implementation times of SW offshoring, assuming that its consequences would be more visible after at least 1 year and would be well established after 3 years.

\section{Analyses and findings}

\section{Measure validation}

To assess measurement scale validity and reliability, we performed a confirmatory factor analysis (CFA) using LISREL 8.80 (Jöreskog and Sörbom, 2007). We adopted maximum likelihood estimation and judged model fit using common indicators (Diamantopoulos and Siguaw, 2009). Our measurement model has a good fit with the data. Table 2 shows the measurement model statistics and inter-construct correlations. It reveals that the key fit indicators of our measurement model are within recommended thresholds. All average variances extracted (AVEs) and composite reliabilities comfortably surpassed the 0.5 and 0.6 thresholds, respectively (Bagozzi and Yi, 1988; Fornell and Larcker, 1981). In addition, all AVEs were higher than the squared correlations among latent constructs, which lends support to the discriminant validity of our measures (Fornell and Larcker, 1981). Furthermore, we assessed discriminant validity using Henseler et al.'s (2015) heterotrait-monotrait ratio of correlations (HTMT) (see Table 3). As Table 3 shows, all HTMT scores are below the 0.85 threshold in absolute value, suggesting sufficient discriminant validity (Hair et al., 2017; Henseler et al., 2015; Voorhees et al., 2016). We therefore concluded that our measures yield sufficient convergent and discriminant validity for model testing.

\section{Common method variance}

We adopted both ex ante and ex post approaches to address the potential issue of common method variance (CMV) (Chang et al., 2010; Podsakoff et al., 2003). In terms of ex ante procedures, respondents were ensured that their responses were anonymous and confidential, that there were no right or wrong answers, and that they should answer as honestly as possible (Chang et al., 2010). Furthermore, we carefully inspected and pilot tested the survey items to ensure that unclear, vague, and unfamiliar terms were not included and that both the questionnaire in its entirety and the individual items were constructed as succinctly as possible (Chang et al., 2010; Harrison et al., 1996; Lindell and Whitney, 2001; Podsakoff et al., 2003). This was done in order to diminish problems regarding respondents' comprehension of the survey. Also, as discussed previously, we used a key informant methodology for data collection via collecting data only from individuals who would have knowledge and experience regarding the issues at hand. Since unfamiliarity with survey questions is a common source of CMV, the use of key respondents contributed to reduce the chances of its occurrence. In addition, we used different scale formats to assess different variables (for instance, we adopted reverse coding, used different scale anchors for different constructs, and utilized various different response formats, such as radio buttons and dropdown menus). We also counterbalanced the order of questions pertaining to different constructs. These procedures render CMV less likely, as they make it more difficult for the respondent to easily combine related items and mentally produce the correlations necessary to produce a CMV-biased pattern of survey responses (Chang et al., 2010).

In terms of ex post approaches, we ran Harman's onefactor test to assess whether results were pervasively affected by CMV. The test produced poor model fit statistics (chisquare $=588.36, p=0.00, \mathrm{df}=77$, root mean square error of approximation $($ RMSEA $)=0.21$, standardized root mean square residual $(R M R)=0.16)$. This diminishes the concerns that our results are a result of CMV. In addition, our model includes various relationships that are not obvious to respondents. In this context, the nonlinearities that derive from the inclusion of interactions corresponding to moderating effects would have made it difficult, if not impossible, for respondents to mentally anticipate the relationships under investigation and form their response patterns accordingly (Palmatier, 2016). Therefore, we concluded that CMV is unlikely to be a problem in this study.

\section{Structural model estimation}

We utilized conventional product-term analysis to test for moderation effects (Ping, 1995). We anticipate that 
Table 2. Model fit indicators, correlation matrix, and measurement scale properties.

\begin{tabular}{|c|c|c|c|c|c|c|c|c|c|c|c|c|}
\hline Model & \multicolumn{2}{|l|}{$\chi^{2}(\mathrm{df})$} & \multicolumn{2}{|l|}{$p$-value } & \multicolumn{2}{|l|}{$\Delta \chi^{2}(d f)$} & \multicolumn{2}{|l|}{ RMSEA } & \multicolumn{2}{|l|}{$\mathrm{CFI}$} & \multicolumn{2}{|l|}{ NFI } \\
\hline Measurement model & \multirow{2}{*}{\multicolumn{2}{|c|}{ II $6.84(7 \mathrm{I})$}} & \multirow{2}{*}{\multicolumn{2}{|c|}{0.00}} & \multirow{2}{*}{\multicolumn{2}{|c|}{-}} & \multicolumn{2}{|l|}{0.07} & \multirow{2}{*}{\multicolumn{2}{|c|}{0.97}} & \multicolumn{2}{|l|}{0.93} \\
\hline \multicolumn{5}{|l|}{ Structural models } & & & & & & & & \\
\hline Model I (constrained model) ${ }^{\mathrm{a}}$ & \multirow{2}{*}{\multicolumn{2}{|c|}{$\begin{array}{l}73.22(43) \\
58.03(4 I)\end{array}$}} & \multirow{2}{*}{\multicolumn{2}{|c|}{$\begin{array}{l}0.00 \\
0.04\end{array}$}} & \multirow{2}{*}{\multicolumn{2}{|c|}{$\begin{array}{l}- \\
15.19(2)^{c}\end{array}$}} & \multirow{2}{*}{\multicolumn{2}{|c|}{$\begin{array}{l}0.07 \\
0.05\end{array}$}} & \multirow{2}{*}{\multicolumn{2}{|c|}{$\begin{array}{l}0.95 \\
0.97\end{array}$}} & \multirow{2}{*}{\multicolumn{2}{|c|}{$\begin{array}{l}0.91 \\
0.93\end{array}$}} \\
\hline Model 2 (unconstrained model) ${ }^{b}$ & & & & & & & & & & & & \\
\hline Measures & I & 2 & 3 & 4 & 5 & 6 & 7 & 8 & 9 & 10 & 11 & 12 \\
\hline I. Organizational commitment & - & & & & & & & & & & & \\
\hline 2. Job complexity & $-0.25^{*}$ & - & & & & & & & & & & \\
\hline 3. Cross-cultural work & $0.31 * *$ & 0.03 & - & & & & & & & & & \\
\hline 4. Perceived organizational valence & $0.74 * *$ & $-0.29 * *$ & 0.13 & - & & & & & & & & \\
\hline 5. Industry (Finance) & $-0.4 \mid * *$ & $0.26 * *$ & 0.07 & $-0.32 * *$ & - & & & & & & & \\
\hline 6. Industry (Retail) & -0.05 & 0.02 & -0.02 & -0.01 & $-0.19 *$ & - & & & & & & \\
\hline 7. Industry (Manufacturing) & $0.18^{*}$ & -0.07 & 0.07 & 0.05 & $-0.21 *$ & $-0.17 *$ & - & & & & & \\
\hline 8. Industry (IT) & -0.02 & -0.02 & -0.13 & -0.04 & $-0.25 * *$ & $-0.20 *$ & $-0.22 * *$ & - & & & & \\
\hline 9. Tenure (<I year) & -0.03 & -0.02 & -0.08 & 0.05 & -0.06 & -0.05 & -0.05 & -0.06 & - & & & \\
\hline 10. Tenure ( $1-3$ years $)$ & -0.02 & 0.08 & $0.20 *$ & -0.03 & 0.04 & -0.02 & 0.06 & -0.08 & -0.07 & - & & \\
\hline II. Recency of offshoring ( $<$ I year) & 0.08 & 0.02 & -0.03 & 0.11 & 0.05 & 0.01 & -0.01 & -0.11 & $0.25 * *$ & 0.01 & - & \\
\hline 12. Recency of offshoring (I-3 years) & 0.10 & -0.14 & -0.07 & 0.09 & $-0.21 *$ & 0.02 & 0.15 & -0.08 & 0.03 & $0.17 *$ & $-0.17 *$ & - \\
\hline Mean & 3.73 & 3.01 & 4.13 & 3.62 & 0.19 & 0.13 & 0.16 & 0.20 & 0.01 & 0.27 & 0.05 & 0.38 \\
\hline Standard deviation & 0.87 & 1.13 & 0.77 & 0.91 & 0.40 & 0.34 & 0.37 & 0.40 & 0.12 & 0.45 & 0.21 & 0.49 \\
\hline $\begin{array}{l}\text { Composite reliability } \\
\text { Average variance extracted }\end{array}$ & $\begin{array}{l}0.87 \\
0.62\end{array}$ & $\begin{array}{l}0.86 \\
0.67\end{array}$ & $\begin{array}{l}0.82 \\
0.61\end{array}$ & $\begin{array}{l}0.85 \\
0.59\end{array}$ & $\begin{array}{l}N A^{d} \\
N A^{d}\end{array}$ & $\begin{array}{l}N A^{d} \\
N A^{d}\end{array}$ & $\begin{array}{l}N A^{d} \\
N A^{d}\end{array}$ & $\begin{array}{l}N A^{d} \\
N A^{d}\end{array}$ & $\begin{array}{l}N A^{d} \\
N A^{d}\end{array}$ & $\begin{array}{l}N A^{d} \\
N A^{d}\end{array}$ & $\begin{array}{l}N A^{d} \\
N A^{d}\end{array}$ & $\begin{array}{l}N A^{d} \\
N A^{d}\end{array}$ \\
\hline
\end{tabular}

RMSEA: root mean square error of approximation; CFI: comparative fit index; NFI: normed fit index; CR: composite reliability; AVE: average

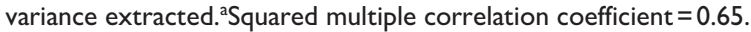

bSquared multiple correlation coefficient $=0.73$.

'Relative to Model I (constrained model), Model 2 exhibits a significant improvement (decrease) in chi-square.

${ }^{\mathrm{N} A}=$ not applicable. Because these three measures are single-item, CR and AVE are not meaningful.

*Correlation is significant at the 0.05 level.

**Correlation is significant at the $0.0 \mathrm{I}$ level.

Table 3. HTMT scores (absolute values).

\begin{tabular}{|c|c|c|c|c|c|c|c|c|c|c|c|}
\hline HTMT scores (absolute values) & I & 2 & 3 & 4 & 5 & 6 & 7 & 8 & 9 & 10 & II \\
\hline \multicolumn{12}{|l|}{ I. Organizational commitment } \\
\hline 2. Cross-cultural work & 0.32 & & & & & & & & & & \\
\hline 3. Perceived organizational valence & 0.74 & 0.09 & & & & & & & & & \\
\hline 4. Job complexity & 0.29 & 0.07 & 0.28 & & & & & & & & \\
\hline 4. Industry (Finance) & 0.41 & 0.08 & 0.32 & 0.22 & & & & & & & \\
\hline 5. Industry (Retail) & 0.05 & 0.02 & 0.01 & 0.03 & 0.19 & & & & & & \\
\hline 6. Industry (Manufacturing) & 0.19 & 0.08 & 0.05 & 0.06 & 0.21 & 0.17 & & & & & \\
\hline 7. Industry (IT) & 0.02 & 0.13 & 0.04 & 0.03 & 0.24 & 0.20 & 0.22 & & & & \\
\hline 8. Tenure $(<\mathrm{I}$ year $)$ & 0.02 & 0.08 & 0.05 & 0.04 & 0.06 & 0.05 & 0.05 & 0.06 & & & \\
\hline 9. Tenure (I-3 years) & 0.03 & 0.19 & 0.03 & 0.08 & 0.04 & 0.02 & 0.06 & 0.08 & 0.07 & & \\
\hline 10. Recency of offshoring ( $<$ I year) & 0.08 & 0.02 & 0.11 & 0.01 & 0.05 & 0.01 & 0.01 & 0.11 & 0.25 & 0.01 & \\
\hline II. Recency of offshoring (I-3years) & 0.10 & 0.07 & 0.09 & 0.12 & 0.21 & 0.02 & 0.15 & 0.08 & 0.03 & 0.17 & 0.17 \\
\hline
\end{tabular}

HTMT: heterotrait-monotrait ratio of correlations.

organizational valence moderates the relationships between affective organizational commitment and the perceived increase in (a) job complexity (H2a) and (b) cross-cultural work (H2b). Accordingly, we calculated the required multiplicative terms and entered them into the model equation. In line with established practice, we also included the direct effects of perceived increase in job complexity, cross-cultural work, and perceived organizational valence in the model (Aiken and West, 1991). We further included a number of control variables, namely the firm's industry, the individual's tenure, and the recency of offshoring, that is, the time elapsed since the initiation of offshoring in the individual's business unit. 
To reduce multicollinearity problems associated with the simultaneous inclusion, in the model, of interaction (i.e. product) terms and of the first-order variables used to compute them, we adopted the residual centering procedure (Little et al., 2006). This approach entails regressing a product term onto its corresponding indicators. The residuals which result from the regression are then utilized to represent the interaction effect. Residual centering guarantees full orthogonality between a product term and the indicators from which such product term is derived (Little et al., 2006), thereby addressing the issue of multicollinearity associated with the use of interaction terms.

There is an ongoing debate in the IS literature concerning the suitability of using variance versus covariancebased approaches to test relationships among different constructs and regarding the issues that need to be taken into account when adopting a specific approach (e.g. Goodhue et al., 2012; Kock and Hadaya, 2018; Kock and Lynn, 2012; Qureshi and Compeau, 2009). In this context, researchers frequently highlight sample size and normality of the distribution of the latent constructs as key issues. In line with established IS research (e.g. Titah and Barki, 2009), we adopted covariance-based structural equation modeling using single indicants. The use of single indicants to represent latent variables and interactions among those has been shown to be an effective way of reducing model complexity and, accordingly, enhancing the accuracy of parameter estimates in the case of small sample sizes (Bagozzi and Edwards, 1998; Bagozzi and Heatherton, 1994; Jaccard and Wan, 1996). Single indicants also have the added advantage of being less prone to violate distributional assumptions relative to the individual items from which they are computed (Little et al., 2002).

Specifically, in line with established research in information technology (e.g. Titah and Barki, 2009), we followed a multi-step process. The first step entailed computing single indicants corresponding to the predictor variables that were latent constructs, namely perceived increase in job complexity, cross-cultural work, and perceived organizational valence. This was done via averaging corresponding measurement items (Little et al., 2002). The single indicants were then entered into a measurement model, in which the factor loadings of those indicants were set at 1 and the error variances at $\left[(1-a)^{*} \sigma^{2}\right]$ (Jöreskog and Sörbom, 1993). The dependent variable (affective organizational commitment) was modeled as a latent construct (Jöreskog and Sörbom, 1993). In a second step, the factor loadings and error variances obtained in the first step were used to compute the loadings and error terms of the single indicants corresponding to the interaction terms that were computed to represent the moderating effects. This was done via deploying the equations provided by Ping (1995) (for a detailed illustration, see Titah and Barki (2009)). The above-described procedure is in line with established research in information technology (e.g. Titah and Barki, 2009) and, unlike standard and moderated regression techniques, has the advantage of enhancing model parsimony while allowing the researcher to accurately model the predictors (as well as the interactions among those) as latent constructs. This is because, unlike what happens with standard or moderated regression techniques, the loadings and error variances specified for the single indicants entered into the structural model are a function of the loadings and measurement errors of the latent constructs represented by those single indicants (Jaccard and Wan, 1996; Titah and Barki, 2009). Table 4 reports the covariances among observed variables (i.e. indicators).

We ran two structural models in LISREL 8.80 (Jöreskog and Sörbom, 2007), specifically a constrained model and an unconstrained model. In the case of the constrained (Model 1, Table 2) model, we allowed only for the direct effects to be estimated freely. Accordingly, we fixed the interaction terms at zero. In the case of the unconstrained model (Model 2, Table 2), we allowed for all the effects to be estimated freely. Inspection of Table 2 reveals that the decrease in chisquare associated with moving from the constrained model to the unconstrained model was statistically significant $[\Delta$ chi-square $(\Delta \mathrm{df})=15.19(2), p<0.05]$. Furthermore, the model explained $7.70 \%$ more variance in the dependent variable relative to the constrained model. We thus concluded that the unconstrained model fits the data better than does the constrained model. In addition, the key fit indicators of the unconstrained model were within recommended thresholds (RMSEA $=0.05$; comparative fit index $(\mathrm{CFI})=0.97$; normed fit index $(\mathrm{NFI})=0.93$; non-normed fit index $(\mathrm{NNFI})=0.90)$. These figures suggest a very good fit of the unconstrained model with the data (Diamantopoulos and Siguaw, 2009). We also calculated the statistical power of our model, that is, the probability of not rejecting an incorrect model (Diamantopoulos and Siguaw, 2009). The power associated with the test of close fit (MacCallum et al., 1996) takes the error of approximation into account (Diamantopoulos and Siguaw, 2009). This test is widely used in the Structural Equation Modeling literature (e.g. Kim, 2005; Li and Bentler, 2011; McQuitty, 2004; Yuan et al., 2016) and assumes that models are only approximations of reality - in other words, it is never the case that they fit exactly in the population (Diamantopoulos and Siguaw, 2009). The power of the test associated with close fit yielded the value of 0.55 . This means that, under the hypothetical condition that the model had a mediocre fit in the population, the chances of not detecting it would be less than $50 \%$ (Diamantopoulos and Siguaw, 2009). Relatedly, our model yielded more than 0 degrees of freedom (specifically, 41), which indicates that the model is empirically overidentified (Diamantopoulos and Siguaw, 2009). We were, thus, confident that the unconstrained model was appropriate for hypothesis testing.

\section{Hypotheses testing}

Table 4 depicts the standardized coefficients for both the constrained model and the unconstrained model. It also 


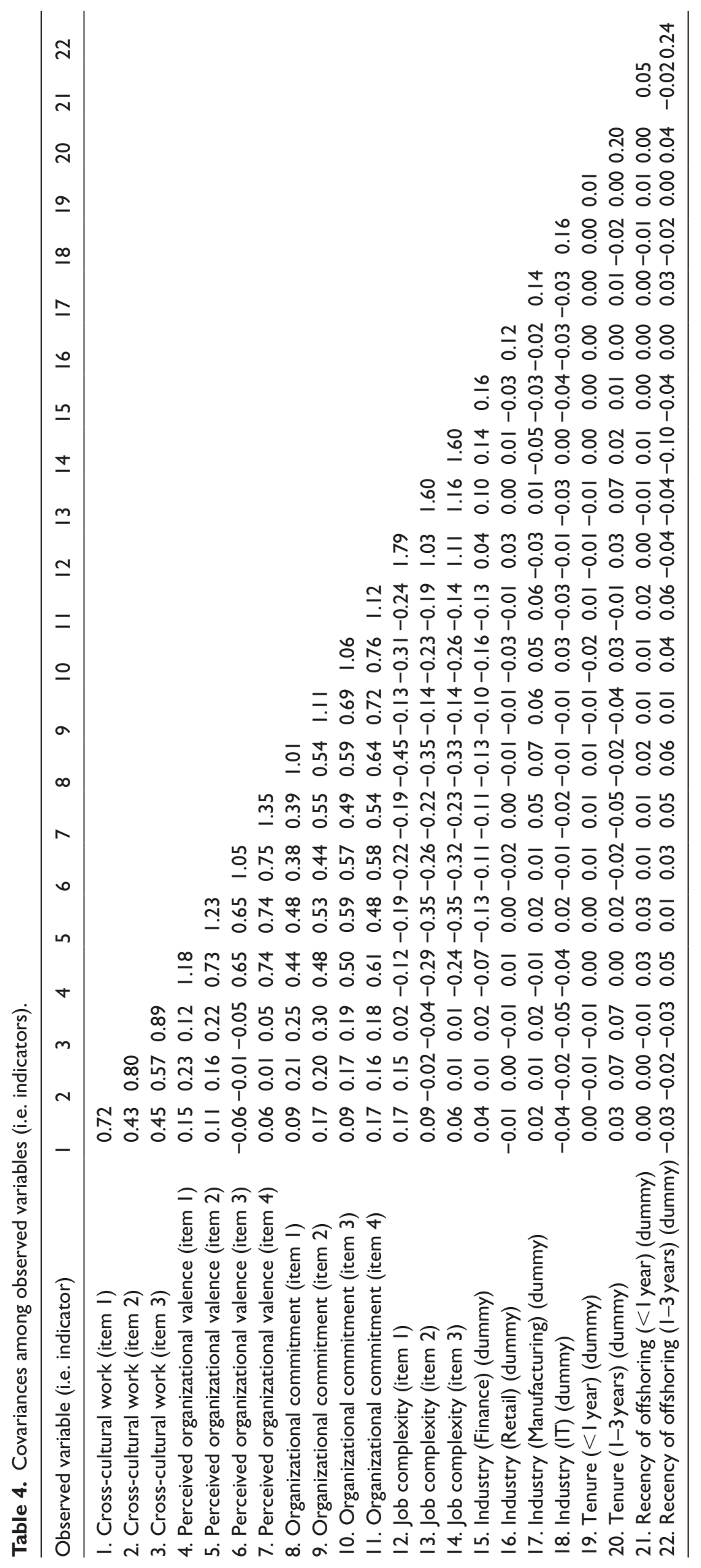


Table 5. Parameter estimates and t-values. ${ }^{a}$

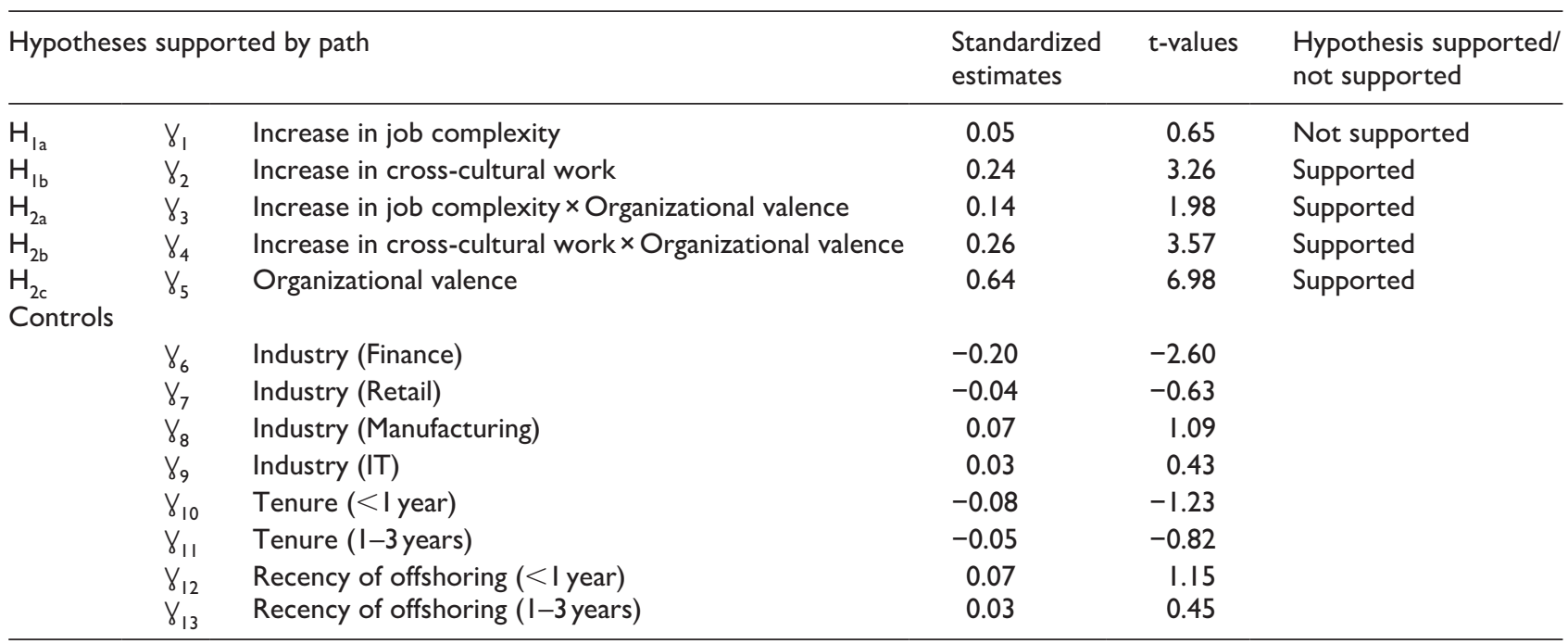

${ }^{\mathrm{a} C r i t i c a l} \mathrm{t}$-value $(5 \%$, one-tailed $)=1.65$; critical $\mathrm{t}$-value $(1 \%$, one-tailed $)=2.33$.

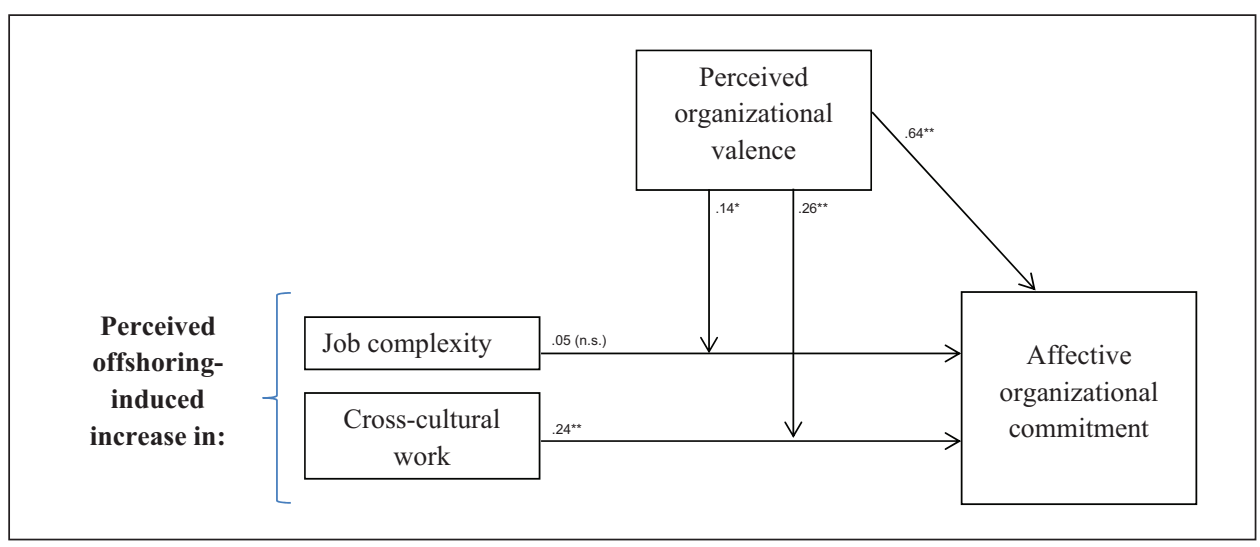

Figure 2. Estimates of path coefficients.

n.s.: not significant.

All $p$-values are based on one-tailed tests. All values correspond to standardized coefficients.

$* p<0.05 ; * * p<0.01$.

displays the corresponding t-values. Since our hypotheses are directional (they predict positive/negative direct/moderating effects), we utilized one-tailed tests to judge the strength and statistical significance of the estimates (Diamantopoulos and Schlegelmilch, 2000). Accordingly, t-values were considered significant at the $5 \%$ and $1 \%$ levels if their absolute values surpassed 1.65 and 2.33 , respectively. As outlined in the previous section, we used the unconstrained model for hypothesis testing.

As can be seen in Table 5 (unconstrained model), with regard to H1a, the coefficient linked to perceived increase in job complexity is not significant $\left(\mathrm{\gamma}_{1}=0.05, \mathrm{t}=0.65\right.$, $p>0.05$ ). Therefore, H1a is not supported. With regard to $\mathrm{H} 1 \mathrm{~b}$, the coefficient associated with perceived increase in cross-cultural work is positive and significant $\left(\mathrm{\gamma}_{2}=0.24\right.$, $\mathrm{t}=3.26, p<0.01)$. Therefore, H1b is supported.
In terms of moderating effects, the interaction between perceived increase in job complexity and organizational valence is significant and positive $\left(\mathrm{\gamma}_{3}=0.14, \mathrm{t}=1.98\right.$, $p<0.05$ ). This result corroborates $\mathrm{H} 2 \mathrm{a}$ (i.e. that organizational valence moderates the relationship between perceived increase in job complexity and affective organizational commitment). The interaction between perceived increase in cross-cultural work and organizational valence is positive and significant $\left(\mathrm{\gamma}_{4}=0.26, \mathrm{t}=3.57, p<0.01\right)$. $\mathrm{H} 2 \mathrm{~b}$ is therefore supported. Finally, the link between perceived organizational valence and affective organizational commitment is positive and significant $\left(\mathrm{X}_{5}=0.64, \mathrm{t}=6.98, p<0.01\right)$. Thus, $\mathrm{H} 2 \mathrm{c}$ is supported. Figure 2 provides an overview of the estimates of path coefficients.

In order to assess if the findings attained were simply a result of cross-correlations among predictors, we also 
tested the effect of each predictor individually via running several more parsimonious models. The corresponding results corroborated the findings of our main model (i.e. all hypotheses (non) supported in the full model were also (non) supported in the smaller models). As such, it can be concluded that our results do not stem from cross-correlations among constructs.

We provide a visual depiction of the moderating results found in the Online Appendix. Specifically, the Online Appendix illustrates the link between job complexity and affective organizational commitment (under high and low levels of perceived organizational valence) and the relationship between cross-cultural work and affective organizational commitment (also under high and low levels of perceived organizational valence).

\section{Discussion}

\section{Interpretation of findings}

Our research explored how perceived offshoring-related changes in onshore managers' work characteristics are related to their affective organizational commitment. To create a foundation for our study, we combined recent insights into offshoring with long-standing evidence on work design. This combination allowed us to single out offshoring-induced increases in specific work characteristics (namely in job complexity and cross-cultural work) and to hypothesize their relationship with affective organizational commitment. Drawing on the organizational change literature, we further hypothesized moderating and direct effects of organizational valence.

The results confirm four of our five hypotheses. We found that a perceived increase in job complexity on its own was not significantly associated with greater organizational commitment, disconfirming Hypothesis 1a. However, we found that job complexity was positively associated with greater affective organizational commitment if individuals believed that the offshoring was beneficial for the organization, thus confirming Hypotheses $2 \mathrm{a}$ on the positive moderating effect of organizational valence. The effect of job complexity on commitment became stronger the greater the perceived organizational valence. Our results also confirm Hypothesis $1 \mathrm{~b}$ and $2 \mathrm{~b}$. A perceived increase in cross-cultural work was associated with higher levels of organizational commitment, and when this association was stronger, the more individuals perceived offshoring to be beneficial for the organization.

We interpret these findings as follows. First, our results on job complexity in relation to commitment contradict tenets by the work design literature, but underscores findings from the offshoring literature that indicate mixed employee responses to offshoring. For some managers, having to "multi-task" to a greater extent and complete more complicated tasks after offshoring (i.e. greater job complexity) may be a welcomed challenge, while others perceive it as stressful. Overall, the extent to which job complexity increased after offshoring did therefore not make a difference for the levels of affective organizational commitment. However, perceived organizational valence changed this relationship. If individuals believed that their efforts served a good purpose by being beneficial to the organization (i.e. perceived organizational valence), they did indeed feel greater organizational commitment. It seems that the challenge of job complexity was, for managers who believed their effort was worth it, a motivation to exert effort on behalf of the organization and maintain membership in the organization, which are two core components of organizational commitment (Mowday et al., 1979: 226).

The finding of a positive association between an increased extent of cross-cultural work and affective organizational commitment concords with Nurmi and Hinds' (2016) observation that global working entails positive outcomes, namely increased job satisfaction, work engagement, and innovative performance. We clearly complement this line of reasoning by demonstrating how cross-cultural work, described more specifically as coordinating work across national boundaries and dealing with cross-cultural differences in work practices and communication styles, also has a positive effect on affective organizational commitment. As observed by Nurmi and Hinds (2016), this emphasis on the positive effects of global work is in contrast to the wealth of studies that stress the challenges and stressors of international interactions at work. As mentioned, there are reports on employees who regard increased cross-cultural work after IS offshoring as an additional burden (Zimmermann and Ravishankar, 2011). In the same vein, cross-cultural work in general has been seen to cause process losses (Stahl et al., 2010) and thereby create hidden costs in IS offshoring (Dibbern et al., 2008). In our study, some managers may have experienced cross-cultural work as a challenge, but overall this work characteristic enhanced rather than hampered managers' organizational commitment. It thus seems that increased cross-cultural work was an accepted or even welcomed challenge, rather than a distressing challenge.

With regard to job complexity and cross-cultural work, our findings clearly support our argument that perceived organizational valence is a moderator of the relationship between offshoring-related changes in work characteristics and organizational commitment. Concerning job complexity, our findings even suggest that organizational valence determines whether there is an effect on organizational commitment at all. Notably, we also found a very strong $(\mathrm{t}-\mathrm{value}=6.98)$ direct association between perceived organizational valence and affective organizational commitment (see Figure 2, arrow linking perceived organizational valence with affective organizational commitment). This supports our assumption that employees who believe that 
the organization's decision to offshore makes sense are likely to develop stronger affective organizational commitment. This finding further strengthens the point that organizational valence is an important factor that should not be neglected when managing the psychological consequences of offshoring.

\section{Research contributions}

When looking at IS offshoring research, we see some rich evidence on the effect of IS offshoring on onshore individuals' work (e.g. Zimmermann and Ravishankar, 2016) and attitudes (Metiu, 2006; Zimmermann et al., 2013; Zimmermann and Ravishankar, 2011, 2016). However, this research has not applied the well-developed constructs and measures of work characteristics and organizational valence. By importing these constructs into IS offshoring research, we are able to compare our offshoring-related findings in more detail to the literatures on work design and organizational change, thereby adding new explanations to prior findings on offshoring, extending work design theory, and opening avenues for new research.

First, our study suggests that the reactions of onshore employees to increased job complexity and cross-cultural work requirements through offshoring may result not only in varied efforts to support the IS offshoring operation (e.g. Metiu, 2006; Zimmermann and Ravishankar, 2011, 2016), but also affects individuals' affective organizational commitment, a relationship suggested by the work design literature. This effect is fundamental not only for the success of particular IS projects but also for the organization more widely, given that individuals' organizational commitment plays a central role for organizational-level outcomes such as employee turnover and firm performance (Meyer et al., 2002). Future offshoring research should therefore include organizational commitment as an outcome variable. More broadly, we recommend exploring whether offshoring yields individual-level attitudinal outcomes that concern not just the offshoring operation, but the organization more widely.

Second, we contribute to offshoring and work design research by demonstrating the importance of organizational valence as a moderator. Our finding that increased crosscultural work is a welcomed challenge that is associated with increased affective organizational commitment is somewhat in contrast to prior findings suggesting that managers sometimes do not appreciate increased cross-cultural working requirements and may react by withdrawing their support for the IS offshoring operation (Metiu, 2006; Zimmermann et al., 2013; Zimmermann and Ravishankar, 2011, 2016). However, our results also indicate that the variation in employees' reactions to offshoring-induced changes depends on employees' perceptions of organizational valence. Regarding increased cross-cultural work, perceived organizational valence increases resultant organizational commitment.
Regarding increased job complexity in turn, organizational valence even makes a crucial difference. Our findings suggest that increased job complexity strengthens organizational commitment only if individuals believe that offshoring is beneficial for the organization. By adding perceived organizational valence as a moderator, we hence offer an explanation for the varied employee reactions to offshoringrelated changes to their work. Demonstrating the importance of this moderator also contributes to the work design literature, as it contradicts its tenet that increased job complexity is generally associated with positive attitudinal outcomes. We differentiate this tenet by adding that, at least in the offshoring context, increased job complexity on its own does not enhance organizational commitment, but it does so only in the presence of perceived organizational valence.

As offshoring is a relatively recent phenomenon that is still controversial in public debates, employees may in this context be particularly alert to consequences for themselves as well as the organization including organizational benefits (such as potential cost savings) as well as disadvantages (such as efficiency losses). Contextualizing JCM within offshoring thus allowed us to surface the importance of perceived organizational valence as a moderator. Further research is needed to examine whether organizational valence has the same effect in other contemporary work contexts. Our findings suggest that in any case, organizational valence should be included as a variable when examining the link between work characteristics and attitudinal outcomes. Omitting this variable may yield contradictory results at least in the offshoring setting, but possibly also beyond.

Our third contribution concerns the interaction between individual and organizational level consequences of offshoring. Our finding that perceived organizational valence moderates the relationship between changed work characteristics and organizational commitment implies that individuals are concerned not only about the consequences that organizational changes have directly for themselves but also whether these changes benefit the organization. This contradicts previous claims that messages about organizational benefits are not salient to individuals unless their own job requirements are affected (Burke and Litwin, 1992; Caldwell, 2013). In our IS offshoring scenario, we capture the relevance of organizational-level change to the individual by examining resultant changes in individuals' work characteristics. In addition, we demonstrate that individuals react to these changes in work characteristics differently depending on the extent to which they believe that offshoring benefits the organization. We thus show that organizational-level benefits do matter to individuals and affect their reactions to individual-level changes. We thereby concord with recent observations that organizational- and individual-level changes interact (Vakola, 2013). While this idea has been claimed by the organizational change literature for some while (Holt et al., 2007), it has (to our knowledge) not been included in work design models and offshoring research. 
Assuming an interaction between organizational- and individual-level changes has important implications for our understanding of work design, not only in the context of offshoring but also more generally. It implies that we cannot satisfactorily explain the effect of changes in work characteristics on individual's attitudes by looking at work characteristics alone, but that we also need to factor in how individuals evaluate the associated organizational-level changes. We therefore argue that work design research should take a combined look at individual-level work characteristics and their perceived relation to organizational outcomes, to better understand attitudinal outcomes.

Fourth, our study adds to previous IS literature that has, independent of the offshoring setting, underscored the significance of work design aspects and respective attitudes, behaviors, and performance implications for IS professionals (Dinger et al., 2015; Thatcher et al., 2002, 2006; Tripp et al., 2016). This stream of research has used work characteristics concepts to investigate IS professionals' job satisfaction (Tripp et al., 2016), turnover intention (Dinger et al., 2015; Thatcher et al., 2002, 2006), and work exhaustion (e.g. Moore, 2000; Venkatesh et al., 2020) among other outcomes. We add to this literature by investigating how changes in work characteristics induced by a major organizational change such as offshoring influence onshore managers' affective organizational commitment. Our findings point to additional ways in which work design theory can be used to yield relevant insights for the IS field. We have highlighted that increased job complexity and cross-cultural work are current phenomena induced by IS offshoring and have explained their varied effects on organizational commitment as attitudinal outcome. IS work is however evolving continuously also outside the offshoring context, and many of these changes could be captured using work design concepts, lending categories to describe changing IS work characteristics, and explanations of their relation to attitudinal and behavioral outcomes.

In line with this approach, a recent focus on new work characteristics in the IS context has been on agile software development methods. Agile methods have been found to be positively related job satisfaction (Tripp et al., 2016), to job autonomy, supervisor support, and affective organizational commitment (Prommegger et al., 2019), and clearer and more congruent role perceptions, which can reduce work exhaustion (Venkatesh et al., 2020). Our findings suggest that software development methods may also be related to other job characteristics and additional outcomes. For example, given that agile development methods are particularly useful for complex projects (Venkatesh et al., 2020), it is worth examining whether they are also tied to high job complexity and thereby affect organizational commitment. In the offshoring context, future research could examine whether offshoring-induced changes to job complexity or cross-cultural work vary with different software development methods (such as agile vs non-agile methods) and yield different outcomes concerning organizational commitment or other employee attitudes.

Taking a wider outlook, our study has addressed IS offshoring as a particular, important context of global working, demonstrating that IS offshoring affects not only the nature of contemporary work of onshore managers (as described in prior research), but also their resultant organizational commitment. As mentioned before, we thereby answer recent calls for more insights into the changing nature of work and for taking into account today's global work environment (Barley et al., 2017; Grant and Parker, 2009; Oldham and Hackman, 2010; Parker, 2014; Parker et al., 2017). Through our combined attention to IS offshoring and work characteristics, we thus help widen the scope of work design and IS offshoring research.

\section{Implications for practitioners}

Our findings suggest that senior managers who are responsible for designing IS offshoring operations have to consider carefully how offshoring affects onshore managers' work. While they can assume that increased job complexity and cross-cultural work requirements can enhance onshore managers' organizational commitment, they will, at the same time, have to ensure that employees perceive the organizational benefits of offshoring. This is important for supporting employees' affective organizational commitment after offshoring. As often stressed in the organizational change literature, organizational change such as offshoring needs to be informed by, and communicated clearly to, employees at all levels. The consequences of offshoring for individuals' work characteristics need to be made clear (see Caldwell, 2013), and the benefits for the organization need to be explained in detail. Importantly, employees at lower levels may experience inefficiencies in their collaboration with offshore sites (e.g. due to additional coordination and intercultural interaction costs, see Dibbern et al., 2008) that higher level managers may not be aware of. A participative approach to designing the IS offshoring strategy will therefore be valuable, allowing employees to contribute their experience to the design of the strategy, helping to avoid inefficiencies, and achieve greater organizational benefits. This participative approach could set the ground for employees' belief in the organizational benefit of offshoring and would encourage employees to react to increases in job complexity and cross-cultural work by increased organizational commitment.

\section{Limitations and future research}

Our study has several limitations which set directions for future research. Using retrospective accounts is a common method in IS and Management research (e.g. Weber and Pliskin, 1996; Weigelt, 2009), but it is also well known to create potential response biases. Due to limited information 
processing capacity, people imperfectly recall past events, and their recalls can be influenced by their implicit or espoused theories when they reconstruct the past (see Huber and Power, 1985). Following the recommendations by Huber and Power (1985), we therefore framed the survey questions in a way to minimize these biases. Where available, we used highly structured, pre-tested questions which inhibit misinterpretation of questions and the imposition of respondents' theories. Moreover, we asked our respondents explicitly to indicate changes that were due to the instance of offshoring. Irrespective of these safeguards against biases, future research would benefit from a longitudinal design that uses before and after measures at certain intervals to assess changes and consequences in real time.

The cross-sectional nature of our data did not allow us to assess causality empirically (see Antonakis et al., 2010; Van Der Weele, 2015). As discussed before, we circumvented this problem by differentiating between the particular times that respondents should refer to in their answers concerning different variables. For example, we measured participants' organizational commitment after offshoring, but perceived organizational valence at the time when offshoring was first implemented. This temporal differentiation served to tap on the direction of causation. Nevertheless, future research would benefit from collecting data on independent variables and on the dependent variable at different points in time to empirically test for the direction of causality.

Our sample was restricted to UK managers involved in IS offshoring. While the United Kingdom is a prime country involved in offshoring, additional factors may come into play in other country contexts. For example, general attitudes toward offshoring may be more negative in the United States, which could impinge upon resultant organizational commitment. Public denouncements of offshoring and massive concerns regarding job losses indicate a negative attitude prevailing in the United States (Khan and Lacity, 2014). These concerns about offshoring effects on US employment and salaries are vividly reflected in the words of Paul Krugman: "It's hard to avoid the conclusion that growing U.S. trade with third world countries reduces the real wages of many and perhaps most workers in this country" (The New York Times, 2007).

Our findings on changes in work characteristics also need further consolidation. Particularly our results regarding cross-cultural work need to be replicated in other studies, as they relied on our new scale. It is also worth examining whether non-managerial employees compared to managers experience other changes in their work characteristics and react to them differently, for example, if they are less attracted to increased job complexity and less used to cross-cultural work. A similarly interesting avenue of research would be to investigate effects on other outcomes in the JCM. While individuals' organizational commitment is paramount for organizations, offshoring may also have consequences for outcomes such as job satisfaction or individual performance, as mentioned before. In addition, there is still a need to explore the role of psychological states (e.g. experienced meaningfulness) in the link between changed work characteristics and affective organizational commitment. By examining other offshoring-induced changes in work characteristics, consequences for other outcomes, and the role of psychological states, future research could arrive at a more complete understanding of how managers react to offshoring-related changes to the nature of their work.

\section{Acknowledgements}

We would like to thank Prof. Ilan Oshri for enabling us to conduct this research during his leadership of the Centre for Global Sourcing and Shared Services at Loughborough University. We would also like to thank the anonymous reviewers for their helpful comments.

\section{Declaration of conflicting interests}

The author(s) declared no potential conflicts of interest with respect to the research, authorship, and/or publication of this article.

\section{Funding}

The author(s) received no financial support for the research, authorship, and/or publication of this article.

\section{ORCID iD}

Angelika Zimmermann (iD https://orcid.org/0000-0002-00674537

\section{Supplemental material}

Supplemental material for this article is available online.

\section{References}

Abbott P, Zheng Y, Du R, et al. (2013) From boundary spanning to creolization: A study of Chinese software and services outsourcing vendors. The Journal of Strategic Information Systems 22(2): 121-136.

Aiken L and West SG (1991) Multiple Regression: Testing and Interpreting Interactions. Thousand Oaks, CA: SAGE.

Antonakis J, Bendahan S, Jacquart P, et al. (2010) On making causal claims: A review and recommendations. The Leadership Quarterly 21(6): 1086-1120.

Aspray W, Mayadas F and Vardi MY (2006) Globalization and Offshoring of Software: A Report of the ACM Job Migration Task Force. New York: Association for Computing Machinery.

Avison D and Banks P (2008) Cross-cultural (mis)communication in IS offshoring: Understanding through conversation analysis. Journal of Information Technology 23(4): 249-268.

Bagozzi RP and Edwards JR (1998) A general approach for representing constructs in organizational research. Organizational Research Methods 1(1): 45-87.

Bagozzi RP and Heatherton TF (1994) A general approach to representing multifaceted personality constructs: Application to state self-esteem. Structural Equation Modeling: A Multidisciplinary Journal 1(1): 35-67. 
Bagozzi RP and Yi Y (1988) On the evaluation of structural equation models. Journal of the Academy of Marketing Science 16(1): 74-94.

Barley SR, Bechky BA and Milliken FJ (2017) The changing nature of work: Careers, identities, and work lives in the 21 st century. Academy of Management Discoveries 3(2): $111-115$.

Beulen E (2010) Long-held perceptions of the consequences of IT offshoring will become a reality: Fewer IS jobs in developed countries. Journal of Information Technology 25(4): 376-377.

Burke WW and Litwin GH (1992) A causal model of organizational performance and change. Journal of Management 18(3): 523-545.

Caldwell SD (2013) Are change readiness strategies overrated? A commentary on boundary conditions. Journal of Change Management 13(1): 19-35.

Carmel E and Tjia P (2005) Offshoring Information Technology: Sourcing and Outsourcing to a Global Workforce. Cambridge: Cambridge University Press.

Chang S-J, Van Witteloostuijn A and Eden L (2010) From the editors: Common method variance in international business research. Journal of International Business Studies 41(2): 178-184.

Davis G, Ein-Dor P, King WR, et al. (2006) IT offshoring: History, prospects and challenges. Journal of the Association for Information Systems 7(11): 770-795.

Davis-Blake A and Broschak JP (2009) Outsourcing and the changing nature of work. Annual Review of Sociology 35: 321-340.

Diamantopoulos A and Schlegelmilch B (2000) Taking the Fear Out of Data Analysis. Bournemouth: Thomson Learning.

Diamantopoulos A and Siguaw J (2009) Introducing LISREL. London: SAGE.

Dibbern J, Winkler J and Heinzl A (2008) Explaining variations in client extra costs between software projects offshored to India. MIS Quarterly 32(2): 333-366.

Dinger M, Thatcher JB, Treadway D, et al. (2015) Does professionalism matter in the IT workforce? An empirical examination of IT professionals. Journal of the Association for Information Systems 16(4): 281-313.

Fedor DB, Caldwell S and Herold DM (2006) The effects of organizational changes on employee commitment: A multilevel investigation. Personnel Psychology 59(1): 1-29.

Fornell C and Larcker DF (1981) Evaluating structural equation models with unobservable variables and measurement error. Journal of Marketing Research 18(1): 39-50.

Goo J, Kishore R, Rao HR, et al. (2009) The role of service level agreements in relational management of information technology outsourcing: An empirical study. MIS Quarterly 33(1): 119-145.

Goodhue DL, Lewis W and Thompson R (2012) Does PLS have advantages for small sample size or non-normal data? MIS Quarterly 36(3): 981-1001.

Goodman SE and Ramer R (2007) Global sourcing of IT services and information security: Prudence before playing. Communications of the Association for Information Systems 20(1): 812-823.

Goos M, Manning A and Salomons A (2014) Explaining job polarization: Routine-biased technological change and offshoring. American Economic Review 104(8): 2509-2526.
Grant AM and Parker SK (2009) Redesigning work design theories: The rise of relational and proactive perspectives. The Academy of Management Annals 3(1): 317-375.

Gupta A (2010) Offshoring, IS employment and the IS discipline: Additional considerations. Journal of Information Technology 25(4): 378-379.

Hackman JR and Oldham GR (1975) Development of the job diagnostic survey. Journal of Applied Psychology 60(2): 159-170.

Hackman JR and Oldham GR (1980) Work Redesign. Reading, MA: Addison-Wesley.

Hair JF Jr, Matthews LM, Matthews RL, et al. (2017) PLS-SEM or CB-SEM: Updated guidelines on which method to use. International Journal of Multivariate Data Analysis 1(2): $107-123$

Harrison DA, McLaughlin ME and Coalter TM (1996) Context, cognition, and common method variance: Psychometric and verbal protocol evidence. Organizational Behavior and Human Decision Processes 68(3): 246-261.

Hartline M, Maxham J and McKee D (2000) Corridors of influence in the dissemination of customer-oriented strategy to customer contact service employees. Journal of Marketing 64(2): 35-50.

Henseler J, Ringle CM and Sarstedt M (2015) A new criterion for assessing discriminant validity in variance-based structural equation modelling. Journal of the Academy of Marketing Science 43(1): 115-135.

Hinds P, Liu L and Lyon J (2011) Putting the global in global work: An intercultural lens on the practice of cross-national collaboration. The Academy of Management Annals 5(1): 135-188.

Hirschheim R and Newman M (2010) Houston, we've had a problem. . . offshoring, IS employment and the IS discipline: Perception is not reality. Journal of Information Technology 25(4): 358-372.

Holt DT, Armenakis AA, Feild HS, et al. (2007) Readiness for organizational change: The systematic development of a scale. Journal of Applied Behavioral Science 43(2): 232255.

Huber GP and Power DJ (1985) Retrospective reports of strategic-level managers: Guidelines for increasing their accuracy. Strategic Management Journal 6(2): 171-180.

Humphrey SE, Nahrgang JD and Morgeson FP (2007) Integrating motivational, social, and contextual work design features: A meta-analytic summary and theoretical extension of the work design literature. Journal of Applied Psychology 92(5): 1332-1356.

Huselid MA (1995) The impact of human resource management practices on turnover, productivity, and corporate financial performance. Academy of Management Journal 38(3): 635672.

Iverson RD (1996) Employee acceptance of organizational change: The role of organizational commitment. The International Journal of Human Resource Management 7(1): 122-149.

Jaccard J and Wan CK (1996) LISREL Approaches to Interaction Effects in Multiple Regression. Thousand Oaks, CA: SAGE.

Jarvenpaa SL and Mao JY (2008) Operational capabilities development in mediated offshore software services models. Journal of Information Technology 23(1): 3-17.

Johnson J, Lenartowicz T and Apud S (2006) Cross-cultural competence in international business: Toward a definition and 
a model. Journal of International Business Studies 37(4): 525-543.

Jöreskog K and Sörbom D (1993) LISREL 8: Structural Equation Modeling with the SIMPLIS Command Language. Chicago, IL: Scientific Software International, Inc.

Jöreskog K and Sörbom D (2007) LISREL 8.80. Lincolnwood, IL: Scientific Software International, Inc.

Kelly S and Noonan C (2008) Anxiety and psychological security in offshoring relationships: The role and development of trust as emotional commitment. Journal of Information Technology 23(4): 232-248.

Khan SA and Lacity MC (2014) Organizational responsiveness to anti-offshoring institutional pressures. The Journal of Strategic Information Systems 23(3): 190-209.

Kim KH (2005) The relation among fit indexes, power, and sample size in structural equation modeling. Structural Equation Modeling: A Multidisciplinary Journal 12(3): 368-390.

Kock N and Hadaya P (2018) Minimum sample size estimation in PLS-SEM: The inverse square root and gamma-exponential methods. Information Systems Journal 28(1): 227-261.

Kock N and Lynn G (2012) Lateral collinearity and misleading results in variance-based SEM: An illustration and recommendations. Journal of the Association for Information Systems 13(7): 546-580.

Kumar N, Stern LW and Anderson JC (1993) Conducting interorganizational research using key informants. Academy of Management Journal 36(6): 1633-1651.

Li L and Bentler PM (2011) Quantified choice of root-meansquare errors of approximation for evaluation and power analysis of small differences between structural equation models. Psychological Methods 16(2): 116-126.

Lindell MK and Whitney DJ (2001) Accounting for common method variance in cross-sectional research designs. Journal of Applied Psychology 86(1): 114-121.

Little TD, Bovaird JA and Widaman KF (2006) On the merits of orthogonalizing powered and product terms: Implications for modeling interactions among latent variables. Structural Equation Modeling: A Multidisciplinary Journal 13(4): 497519.

Little TD, Cunningham WA, Shahar G, et al. (2002) To parcel or not to parcel: Exploring the question, weighing the merits. Structural Equation Modeling: A Multidisciplinary Journal 9(2): 151-173.

MacCallum RC, Browne MW and Sugawara HM (1996) Power analysis and determination of sample size for covariance structure modeling. Psychological Methods 1(2): 130-149.

McCann L (2014) Disconnected amid the networks and chains: Employee detachment from company and union after offshoring. British Journal of Industrial Relations 52(2): $237-$ 260.

McKay K, Kuntz JR and Näswall K (2013) The effect of affective commitment, communication and participation on resistance to change: The role of change readiness. New Zealand Journal of Psychology 42(1): 29-40.

McQuitty S (2004) Statistical power and structural equation models in business research. Journal of Business Research 57(2): 175-183.

Maertz CP Jr, Wiley JW, LeRouge C, et al. (2010) Downsizing effects on survivors: Layoffs, offshoring, and outsourcing. Industrial Relations: A Journal of Economy and Society 49(2): 275-285.
Mankiw NG and Swagel P (2006) The politics and economics of offshore outsourcing. NBER Working Paper 12389, July. Cambridge, MA: National Bureau of Economic Research.

Metiu A (2006) Owning the code: Status closure in distributed groups. Organization Science 17(4): 418-435.

Meyer JP and Allen NJ (1991) A three-component conceptualization of organizational commitment. Human Resource Management Review 1(1): 61-89.

Meyer JP, Stanley DJ, Herscovitch L, et al. (2002) Affective, continuance, and normative commitment to the organization: A meta-analysis of antecedents, correlates, and consequences. Journal of Vocational Behavior 61(1): 20-52.

Moore JE (2000) One road to turnover: An examination of work exhaustion in technology professionals. MIS Quarterly 24(1): 141-168.

Morgeson FP and Humphrey SE (2006) The Work Design Questionnaire (WDQ): Developing and validating a comprehensive measure for assessing job design and the nature of work. Journal of Applied Psychology 91(6): 1321-1339.

Morris MW, Podolny J and Sullivan BN (2008) Culture and coworker relations: Interpersonal patterns in American, Chinese, German, and Spanish divisions of a global retail bank. Organization Science 19(4): 517-532.

Mowday RT, Steers RM and Porter LW (1979) The measurement of organizational commitment. Journal of Vocational Behavior 14(2): 224-247.

Nakatsu RT and Iacovou CL (2009) A comparative study of important risk factors involved in offshore and domestic outsourcing of software development projects: A two-panel Delphi study. Information \& Management 46(1): 57-68.

Niederman F, Kundu S and Salas S (2006) IT software development offshoring: A multi-level theoretical framework and research agenda. Journal of Global Information Management 14(2): 52-74.

Nurmi N and Hinds PJ (2016) Job complexity and learning opportunities: A silver lining in the design of global virtual work. Journal of International Business Studies 47(6): 631-654.

Oldham GR and Hackman JR (2010) Not what it was and not what it will be: The future of job design research. Journal of Organizational Behavior 31(2-3): 463-479.

Oreg S, Vakola M and Armenakis A (2011) Change recipients' reactions to organizational change: A 60-year review of quantitative studies. The Journal of Applied Behavioral Science 47(4): 461-524.

Ottaviano GIP, Peri G and Wright GC (2013) Immigration, offshoring, and American jobs. American Economic Review 103(5): 1925-1959.

Palmatier RW (2016) Improving publishing success at JAMS: Contribution and positioning. Journal of the Academy of Marketing Science 44(6): 655-659.

Parker SK (2014) Beyond motivation: Job and work design for development, health, ambidexterity, and more. Annual Review of Psychology 65: 661-691.

Parker SK, Van Den Broeck A and Holman D (2017) Work design influences: A synthesis of multilevel factors that affect the design of jobs. Academy of Management Annals 11(1): 267308.

Peccei R, Giangreco A and Sebastiano A (2011) The role of organisational commitment in the analysis of resistance to change: Co-predictor and moderator effects. Personnel Review 40(2): 185-204. 
Pentareddy S and Suganthi L (2015) Building affective commitment through job characteristics, leadership and empowerment. Journal of Management \& Organization 21(3): 307-320.

Ping RA (1995) A parsimonious estimating technique for interaction and quadratic latent variables. Journal of Marketing Research 32: 336-347.

Podsakoff PM, MacKenzie SB, Lee JY, et al. (2003) Common method biases in behavioral research: A critical review of the literature and recommended remedies. Journal of Applied Psychology 88(5): 879-903.

Prommegger B, Huck-Fries V, Wiesche M, et al. (2019) Agile and attached: The impact of agile practices on agile team members' affective organisational commitment. In: 14th international conference on Wirtschaftsinformatik, Siegen, 24-27 February. Available at: https://aisel.aisnet.org/wi2019/ track07/papers/7/ (accessed 9 July 2020).

Qureshi I and Compeau D (2009) Assessing between-group differences in information systems research: A comparison of covariance-and component-based SEM. MIS Quarterly 33(1): 197-214.

Rafferty AE, Jimmieson NL and Armenakis AA (2013) Change readiness: A multilevel review. Journal of Management 39(1): 110-135.

Robert-Nicaud F (2008) Offshoring of routine tasks and (de) industrialisation: Threat or opportunity-And for whom? Journal of Urban Economics 63(2): 517-535.

Segars AH and Grover V (1998) Strategic information systems planning success: An investigation of the construct and its measurement. MIS Quarterly 22(2): 139-163.

Stahl G, Maznevski ML, Voigt A, et al. (2010) Unraveling the effects of cultural diversity in teams: A meta-analysis of research on multicultural work groups. Journal of International Business Studies 41(4): 690-709.

Stouten J, Rousseau DM and De Cremer D (2018) Successful organizational change: Integrating the management practice and scholarly literatures. Academy of Management Annals 12(2): 752-788.

Thatcher JB, Liu Y, Stepina LP, et al. (2006) IT worker turnover: An empirical examination of intrinsic motivation. $A C M$ SIGMIS Database 37(2-3): 133-146.

Thatcher JB, Stepina LP and Boyle RJ (2002) Turnover of information technology workers: Examining empirically the influence of attitudes, job characteristics, and external markets. Journal of Management Information Systems 19(3): 231-261.

The New York Times (2007) Opinion: Trouble with trade, 28 December. Available at: https://www.nytimes. com/2007/12/28/opinion/28krugman.html (accessed 28 February 2019).

Titah R and Barki H (2009) Nonlinearities between attitude and subjective norms in information technology acceptance: A negative synergy? MIS Quarterly 33(4): 827-844.

Tripp JF, Riemenschneider C and Thatcher JB (2016) Job satisfaction in agile development teams: Agile development as work redesign. Journal of the Association for Information Systems 17(4): 267-307.
United Nations (2005) World investment report: Transnational corporations and the internationalization of R\&D, United Nations Conference on Trade and Development, New York and Geneva.

Vakola M (2013) Multilevel readiness to organizational change: A conceptual approach. Journal of Change Management 13(1): 96-109.

Van Der Weele T (2015) Explanation in Causal Inference: Methods for Mediation and Interaction. Oxford: Oxford University Press.

Venkatesh V, Thong JY, Chan FK, et al. (2020) How agile software development methods reduce work exhaustion: Insights on role perceptions and organizational skills. Information Systems Journal 30: 733-761.

Voorhees CM, Brady MK, Calantone R, et al. (2016) Discriminant validity testing in marketing: An analysis, causes for concern, and proposed remedies. Journal of the Academy of Marketing Science 44: 119-134.

Weber R (2004) Editor's comments: Some implications of the year-2000 Era, dot-com Era, and offshoring for information systems pedagogy. MIS Quarterly 28(2): iii-xi.

Weber Y and Pliskin N (1996) The effects of information systems integration and organizational culture on a firm's effectiveness. Information \& Management 30(2): 81-90.

Weigelt C (2009) The impact of outsourcing new technologies on integrative capabilities and performance. Strategic Management Journal 30(6): 595-616.

Weiner BJ (2009) A theory of organizational readiness for change. Implementation Science 4(1): 67.

Welsch H and LaVan H (1981) Inter-relationship between organizational commitment and job characteristics, job satisfaction, professional behaviour, and organizational climate. Human Relations 34(12): 1079-1089.

Wright TA and Bonett DG (2002) The moderating effects of employee tenure on the relation between organizational commitment and job performance: A meta-analysis. Journal of Applied Psychology 87(6): 1183-1190.

Yuan KH, Chan W, Marcoulides GA, et al. (2016) Assessing structural equation models by equivalence testing with adjusted fit indexes. Structural Equation Modeling: A Multidisciplinary Journal 23(3): 319-330.

Zimmermann A and Ravishankar MN (2011) Collaborative IT offshoring relationships and professional role identities: Reflections from a field study. Journal of Vocational Behavior 78(3): 351-360.

Zimmermann A and Ravishankar MN (2014) Knowledge transfer in IT offshoring relationships: The roles of social capital, efficacy and outcome expectations. Information Systems Journal 24(2): 167-202.

Zimmermann A and Ravishankar MN (2016) A systems perspective on offshoring strategy and motivational drivers amongst onshore and offshore employees. Journal of World Business 51(4): 548-567.

Zimmermann A, Raab K and Zanotelli L (2013) Vicious and virtuous circles of offshoring attitudes and relational behaviours. A configurational study of German IT developers. Information Systems Journal 23(1): 65-88. 


\section{Author biographies}

Angelika Zimmermann is a Senior Lecturer in International Business and Strategy at the School of Business and Economics, Loughborough University, UK. Her research has appeared in a broad range of journals, including the Journal of World Business, Journal of Vocational Behavior, International Journal of Human Resource Management, Information Systems Journal, Journal of Information Technology, Journal of Strategic Information Systems, and International Journal of Management Reviews.

Eleni Lioliou is a Lecturer in International Business and Strategy at the School of Business and Management at Queen
Mary, University of London. She has published her research in the Journal of World Business, Journal of Information Technology, Journal of Strategic Information Systems, Information Systems Journal, and International Business Review.

Joao Oliveira is a Lecturer in Marketing and Retailing at the School of Business and Economics, Loughborough University, UK. His research interests include Export Performance, Innovation, Offshoring, Corporate Social Responsibility, Entrepreneurial Orientation, and Digital Marketing. Joao's research has appeared in journals, namely International Marketing Review, Journal of Business Research, and International Business Review. 